\title{
Dietary assessment methods in epidemiologic studies
}

\author{
Jee-Seon Shim ${ }^{1}$, Kyungwon $\mathrm{Oh}^{2}$, Hyeon Chang Kim ${ }^{1,3}$ \\ ${ }^{1}$ Cardiovascular and Metabolic Diseases Etiology Research Center, Yonsei University College of Medicine, Seoul; ${ }^{2}$ Division of Health and \\ Nutrition Survey, Korea Centers for Disease Control and Prevention, Osong; ${ }^{3}$ Department of Preventive Medicine, Yonsei University College of \\ Medicine, Seoul, Korea
}

\begin{abstract}
Diet is a major lifestyle-related risk factor of various chronic diseases. Dietary intake can be assessed by subjective report and objective observation. Subjective assessment is possible using open-ended surveys such as dietary recalls or records, or using closed-ended surveys including food frequency questionnaires. Each method has inherent strengths and limitations. Continued efforts to improve the accuracy of dietary intake assessment and enhance its feasibility in epidemiological studies have been made. This article reviews common dietary assessment methods and their feasibility in epidemiological studies.
\end{abstract}

KEY WORDS: Dietary assessment, Food frequency questionnaire, 24-hour dietary recall, Dietary record

\section{INTRODUCTION}

Diet is a major lifestyle-related risk factor of a wide range of chronic diseases. Changes in dietary habits have been found to reduce cancer incidence by one-third [1]. Dietary information has been useful in cardiovascular disease risk prediction [2] and consuming a nutrient-dense diet was associated with a low risk of all-cause mortality [3]. Contrary to other lifestyle risk factors (e.g., smoking), dietary exposures are very difficult to measure because all individuals eat foods, even if the amount and the kind of food consumed is various between subjects, and people rarely perceive what they eat and how much they do [4]. Inaccurate dietary assessment may be a serious obstacle of understanding the impact of dietary factors on disease.

Specific biochemical markers have been used as a surrogate to measure the dietary intake of selected nutrients or dietary components in epidemiological studies [5-7]. Previous studies

\section{Correspondence: Hyeon Chang Kim}

Department of Preventive Medicine, Yonsei University College of Medicine, Cardiovascular and Metabolic Diseases Etiology Research Center,

50 Yonsei-ro, Seodaemun-gu, Seoul 120-752, Korea

Tel: +82-2-2228-1873, Fax: +82-2-392-8133, E-mail: hckim@yuhs.ac

Received: Jun 2, 2014, Accepted: Jul 22, 2014, Published: Jul 22, 2014

This article is available from: http://e-epih.org/

(C) 2014, Korean Society of Epidemiology

(C) This is an open-access article distributed under the terms of the Creative Commons Attribution License (http://creativecommons.org/licenses/by/3.0/), which permits unrestricted use, distribution, and reproduction in any medium, provided the original work is properly cited. have found these markers to be highly correlated with dietary intake levels, free of a social desirability bias, independent of memory, and not based on subjects' ability to describe the type and quantity of food consumed [8]. Thus, these biochemical markers may provide more accurate measures than dietary intake estimates do. However, a number of biomarkers have been known to provide integrated measures reflecting their absorption and metabolism after consumption, and they are also affected by disease or homeostatic regulation, thus their values cannot be translated into the subject's absolute dietary intake [9]. Moreover, the results based on biomarkers cannot provide dietary recommendations to modify a subject's dietary habit. Thus, direct assessment of dietary intake may be more informative than biomarkers are $[8,10]$.

Among the available dietary assessment methods, the food frequency questionnaire (FFQ) has been widely used in large epidemiological studies since the 1990s. After doubts of their accuracy were raised in the 2000s [11,12], numerous changes to the assessment methods have been made. Some researchers have shifted their focus and concentrated their efforts to improve the feasibility and accuracy of open-ended dietary assessment methods rather than improve the FFQ or further find relevant biomarkers. Other researchers have concentrated their efforts to enhance the accuracy of the FFQ. Assessing dietary exposure accurately with limited resources remains a challenge for researchers. Thus, we aimed to review common methods for dietary assessment and their feasibility in epidemiological studies. 


\section{DIETARY ASSESSMENT BY OBJECTIVE OBSERVATION}

Table 1 summarizes the available dietary assessment methods, including the methods, collected data, strengths, and limitations considering a conservative approach. Dietary intake can be assessed by objective observation using a duplicate diet approach or food consumption record by a trained research staff. The duplicate diet method collects duplicate samples of a subject's normal diet, and then analyzes it to estimate potential dietary exposures. This method has been mainly used to measure exposure to environmental contaminants such as phthalates and polycyclic aromatic hydrocarbons in foods and beverages [13]. Food consumption record collects dietary information on subjects' food preparation and consumption in their home with the objective observation of skilled field workers. This method is useful in developing countries, especially among those with a low literacy rate or those who prepare a substantial portion of their food at home. In South Korea, the National Nutrition Survey had surveyed households by this direct method to monitor national food consumption from 1969 to 1995 [14]. Well-trained staffs observed and recoded all foods prepared and consumed in the surveyed household for two consecutive days. All data were collected at the household level, thus no information on how foods were consumed by each individual within household or about foods consumed outside the home were collect- ed. Thus, each individual's consumption was indirectly estimated using data on the number, age, and sex of residents in each household sharing the recorded food [15]. With improvement in economic status, increase in eating-out, and advancement in the individual dietary assessment techniques, assessment at the individual level has become widespread in nutritional epidemiological settings.

\section{DIETARY ASSESSMENT BY SUBJECTIVE REPORT}

Subjective dietary assessment methods that assess an individual's intake include the 24-hour dietary recall (24HR), dietary record (DR), dietary history, and FFQ. Data are collected with the help of a trained interviewer or by self-report.

\section{Twenty-four-hour dietary recall and dietary record in a conservative approach}

The 24HR and DR are completely open-ended surveys and collect a variety of detailed information about food consumed over a specific period. The $24 \mathrm{HR}$ is conducted in an in-depth interview manner and typically requires 20 to 30 minutes to complete a single day recall. Detailed data about food preparation methods, ingredients used in mixed dishes, and the brand name of commercial products may be required according to the

Table 1. Dietary assessment methods in epidemiological studies

\begin{tabular}{|c|c|c|c|c|c|c|}
\hline & $\begin{array}{l}\text { Duplicate diet } \\
\text { approach }\end{array}$ & $\begin{array}{l}\text { Food consumption } \\
\text { record }\end{array}$ & $\begin{array}{l}\text { 24-Hour dietary } \\
\text { recall }\end{array}$ & Dietary record & Dietary history & $\begin{array}{l}\text { Food frequency } \\
\text { questionnaire }\end{array}$ \\
\hline Methods & $\begin{array}{l}\text { Collection of dupli- } \\
\text { cate diet sample } \\
\text { and direct analysis }\end{array}$ & $\begin{array}{l}\text { Objective observa- } \\
\text { tion by trained staff } \\
\text { at the household } \\
\text { level }\end{array}$ & $\begin{array}{l}\text { Subjective measure } \\
\text { using open-ended } \\
\text { questionnaires } \\
\text { administered by a } \\
\text { trained interviewer }\end{array}$ & $\begin{array}{l}\text { Subjective measure us- } \\
\text { ing open-ended, self- } \\
\text { administered question- } \\
\text { naires }\end{array}$ & $\begin{array}{l}\text { Subjective measures } \\
\text { using open- and } \\
\text { closed-ended } \\
\text { questionnaires } \\
\text { administered by a } \\
\text { trained interviewer }\end{array}$ & $\begin{array}{l}\text { Subjective measure } \\
\text { using a predefined, } \\
\text { self- or interviewer- } \\
\text { administered format }\end{array}$ \\
\hline $\begin{array}{l}\text { Collected } \\
\text { data }\end{array}$ & $\begin{array}{l}\text { Actual intake informa- } \\
\text { tion throughout a } \\
\text { specific period }\end{array}$ & $\begin{array}{l}\text { Actual intake informa- } \\
\text { tion throughout a } \\
\text { specific period }\end{array}$ & $\begin{array}{l}\text { Actual intake informa- } \\
\text { tion over the previ- } \\
\text { ous } 24 \text { hours }\end{array}$ & $\begin{array}{l}\text { Actual intake information } \\
\text { throughout a specific } \\
\text { period }\end{array}$ & $\begin{array}{l}\text { Usual intake esti- } \\
\text { mates over a rela- } \\
\text { tively long period }\end{array}$ & $\begin{array}{l}\text { Usual intake estimates } \\
\text { over a relatively long } \\
\text { period (e.g., } 6 \text { months } \\
\text { or } 1 \text { year) }\end{array}$ \\
\hline Strengths & $\begin{array}{l}\text { Measurement of di- } \\
\text { etary exposures } \\
\text { possible (e.g., envi- } \\
\text { ronmental contami- } \\
\text { nants) }\end{array}$ & $\begin{array}{l}\text { Ease of application } \\
\text { among those with } \\
\text { low literacy or those } \\
\text { who prepare most } \\
\text { meals at home }\end{array}$ & $\begin{array}{l}\text { Provides detailed in- } \\
\text { take data; relatively } \\
\text { small respondent } \\
\text { burden (literacy not } \\
\text { required) }\end{array}$ & $\begin{array}{l}\text { Provides detailed intake } \\
\text { data; no interviewer } \\
\text { required; no recall bias }\end{array}$ & $\begin{array}{c}\text { Assesses usual } \\
\text { dietary intake }\end{array}$ & $\begin{array}{l}\text { Assesses usual dietary } \\
\text { intake simply; cost-ef- } \\
\text { fective and time-sav- } \\
\text { ing; suitable for epi- } \\
\text { demiological studies }\end{array}$ \\
\hline Limitations & $\begin{array}{l}\text { Not suitable for large- } \\
\text { scale studies }\end{array}$ & $\begin{array}{l}\text { Individual dietary } \\
\text { consumption not } \\
\text { accurate; Not } \\
\text { suitable among } \\
\text { those frequently } \\
\text { eat outside the } \\
\text { home }\end{array}$ & $\begin{array}{l}\text { Possible recall bias; } \\
\text { trained interviewer } \\
\text { required; possible } \\
\text { interviewer bias; } \\
\text { expensive and time- } \\
\text { consuming; multiple } \\
\text { days required to as- } \\
\text { sess usual intake; } \\
\text { possible changes } \\
\text { to diet if repeated } \\
\text { measures }\end{array}$ & $\begin{array}{l}\text { Relatively large respon- } \\
\text { dent burden (literacy } \\
\text { and high motivation } \\
\text { required, possible } \\
\text { under-reporting); ex- } \\
\text { pensive and time-con- } \\
\text { suming; multiple days } \\
\text { required to assess } \\
\text { usual intake; possible } \\
\text { changes to diet if re- } \\
\text { peated measures }\end{array}$ & $\begin{array}{l}\text { High cost and time- } \\
\text { consuming; not } \\
\text { suitable for epide- } \\
\text { miological studies }\end{array}$ & $\begin{array}{l}\text { Specific to study } \\
\text { groups and research } \\
\text { aims; uses a closed- } \\
\text { ended questionnaire; } \\
\text { low accuracy (recall } \\
\text { bias); requires accu- } \\
\text { rate evaluation of de- } \\
\text { veloped question- } \\
\text { naires }\end{array}$ \\
\hline
\end{tabular}


research question. The amounts of each food consumed are estimated in reference to a common size container (e.g., bowls, cups, and glasses), standard measuring cups and spoons, a threedimensional food model, or two-dimensional aids such as photographs. One advantage of the $24 \mathrm{HR}$ is that a relatively minimal burden is imposed on respondents. However, an inevitable limitation is that all information depends on the respondents' memory and the skills of a well-trained interviewer to minimize recall bias. Conversely, DR collects data by subjects' self-record at the time the food are eaten, thus minimizes reliance on a subjects' memory. To obtain accurate data, however, respondents must be trained before participating the survey. Therefore, a high level of motivation is required and relatively large burden is passed onto the respondents [4,15].

Both methods have a few common strengths. Both use openended questions so that abundant information can be collected and analyzed in various aspects. In addition, both methods can be easily applied to diverse groups with a wide range of eating habits and may be used to estimate the average intake of a certain population. In many countries including South Korea, the $24 \mathrm{HR}$ is the most commonly used in national surveys [16], and both methods are also frequently applied to randomized clinical trials and cohort studies $[17,18]$. However, these methods have limitations when used to study chronic diseases, a major public health concern. One limitation is that both methods are mainly focused on short-term intake, but long-term dietary exposure is especially of interest when investigating chronic diseases. Thus, to measure average intake, multiple 24HRs or DRs are needed. Repeated measurement not only requires a lot of resources and time but survey repetition can also influence a respondents' diet. Previous studies have found some respondents may improve their dietary habits unintentionally through self-reflection. However, some respondents may alter their diet intentionally to avoid a burden on responses or even choose to not report actual intake $[4,15]$. Another limitation spawns from the open-ended format that requires considerable efforts in the course of data collection, entry, and analyses. Each questionnaire requires careful review by the research staff to ensure that all reported data are included. After initial review, all foods and mixed dishes consumed according to the detailed descriptions of the respondents should be matched and coded with the most appropriate food listed in the food composition database. Moreover, the quantity of food consumed should be converted to its actual weights. When the reported information is changed to the corresponding food code and weight, actual intakes can be calculated. These processes tend to be time-consuming, laborious, and highly expensive to implement.

\section{Twenty-four-hour dietary recall and dietary record with} newer technologies

Despite the aforementioned limitations, multiple 24HRs and DRs have inherent strengths in etiologic studies of chronic diseases. First, both methods collect actual intake on specific days. Second, the burden of memory may be less for these methods than that of the FFQ, which requires recall over a long period (e.g., the previous 12 months). Last, usual intake can also be estimated if repeated. Owing to these strengths, innovative technologies focusing on reducing the respondents' burden, improving accuracy, and making multiple self-administrations possible have been recently incorporated to improve their feasibility in epidemiological studies. Recently, several reports have discussed their use and implications in clinical and research settings [1921].

Although many techniques are still under development, major advances have been made. Interactive computer-based technologies, which were introduced relatively early in dietary assessment method development, aims to be a comprehensive system for data collection, coding, entry, and calculation of intakes. Examples includes the Automated Multiple Pass Method (AMPM) for administering the 24HR in the US National Health and Nutrition Examination Survey [22] and a menu-driven standardized 24HR program (called the EPIC-Soft) in the European Prospective Investigation into Cancer and Nutrition study [23] that allow interviewers to collect, probe, and identify reported intake in a standardized manner, thus improving the accuracy of the data, even if they are used in diverse populations. Having limitations in time, location, and the number of interviewers available for each study, these technologies remain relatively costly for implementation in large-scale epidemiological studies.

Considerably overlapped with the computer-based approach, web-based technologies enable researchers to collect data regardless of a time and a location, assuming internet access is available. Recently the National Cancer Institute in the US. has developed an internet-based technique, called the Automated Self-Administered 24HR that is based on the AMPM approach [24]. This internet-based technique includes an online tutorial, digital images for food identification and portion-size estimation, and various audio files. Thus, those with low literacy can easily complete the survey, and researchers can collect real-time data. Other internet-based technologies designed for face-toface, standardized interview administration have been developed, such as the Diet Evaluation System (DES) that was developed in South Korea [25].

In addition, mobile phone applications that allow users to enter dietary intake data have been released. Subjects can manually record their diet by choosing corresponding items from a pre-defined list of foods and beverages, and the quantity of food consumed can be recorded by selecting from pre-defined por- 
tion sizes [26]. In South Korea, SmartDiet is an application that was developed for dietary management and education, and this application have been evaluated for their effectiveness and feasibility in clinical settings [27]. Multiple functions embedded in a mobile device can be used to collect data. In Japan, the mobile phone application (called Wellnavi) uses the subject's camera and mobile phone card to report everything that was consumed by sending images before and after eating to the study dietitian [28]. In addition, voice recording such as the Spoken Diet Records has been used to collect data [29]. In Australia, Nutricam allows subjects to capture an image of foods and drinks before consumption and verbally describe the items in the image [30]. Then, subjects upload both the image and voice file to a website for analysis [30]. Recently a wearable electronic device that resembles a necklace includes a camera, microphone, and several other sensors has been introduced [31]. This technology uses the video recording to collect dietary information, and the software identifies eating episode and estimates the amount consumed in the video file. Then, final dietary intakes are calculated automatically. This method is likely to minimize the burden of the subjects using objective observation; however, the technology is still in the experiment stage for using in researches.

Most state-of-the-art technologies must give enormous potentials to be adapted as a major dietary assessment tool in various epidemiological studies to the conservative open-ended methods depending on paper and pencil surveys $[19,20,24,32,33]$. Table 2 summarizes the strengths and limitations of dietary assessment methods with newer techniques. Software development and the required hardware need high costs in the early stage of the research. However, only if they are prepared, DRs and 24HRs with innovative technologies may reduce their costs and resources for organizing study as well as collecting and handling data, improve consistency of data, collect data in real time and calculate dietary intakes automatically, and allow respondents to focus on dietary assessment $[20,23,25,32,33]$. While the feasibility of multiple 24HRs and DRs in epidemiological studies has considerably improved with the help of these new technologies, there are still some limitations. First, these meth- ods may be difficult to apply to certain populations who are not familiar with innovative technologies or new devices [32]: Training subjects on how to use these technologies and use a computer including accessing the internet is also required [25]. Furthermore, technical problems in data transfer, storage, battery life, and other concerns must be improved [31]. Most importantly, these new methods do not seem to overcome the methodological problems related to self-report. A previous report found that subjects still had difficulties in recalling and reporting their diet, underreported in repeated assessments, and altered food intake when they knew the survey date in advance [19]. For these reasons, open-ended methods with new technologies have not yet been widely implemented as the primary assessment tool in epidemiological studies.

\section{Dietary history}

To assess individual long-term dietary intake, Burke [34] developed a dietary history method in 1947. This method requires that subjects complete a 24HR, 3-day food diary, and checklist of foods usually consumed. Highly skilled professionals are required to collect information on the participant's usual diet using an in-depth interview (approximately 90 minutes to complete).Thus, this method is rarely used in epidemiological studies.

\section{Food frequency questionnaire}

The FFQ is an advanced form of the checklist in dietary history method, and asks respondents how often and how much food they ate over a specific period [4]. Presenting about 100 to 150 foods, this questionnaire takes 20-30 minutes to complete and can self-administered or collected via interview. This method enables the assessment of long-term dietary intakes in a relatively simple, cost-effective, and time-efficient manner. Thus, various FFQs have been widely employed as a practical instrument since the 1990s [35-37]. FFQs should be developed specifically for each study group and research purposes because diet may be influenced by ethnicity, culture, an individual's preference, economic status, etc. [38]. In South Korea, approximately 20 FFQs have been developed and used in epidemiological studies.

Table 2. Strengths and limitations of new techniques in dietary assessment

\begin{tabular}{|c|c|c|c|}
\hline & 24-hour dietary recall & Dietary record & Food frequency questionnaire \\
\hline Required technology & Software, internet, etc. & $\begin{array}{l}\text { Software, internet, PDA, mobile phone, } \\
\text { application, etc. }\end{array}$ & $\begin{array}{l}\text { Skip algorithms, questions that ask for mul- } \\
\text { tiple details, pictures of foods, etc. }\end{array}$ \\
\hline Strengths & $\begin{array}{l}\text { Standardized data collection possible } \\
\text { (reducing interviewer bias); likely reduce } \\
\text { time and cost; improve feasibility }\end{array}$ & $\begin{array}{l}\text { Standardized, real-time data collection } \\
\text { possible; likely reduce time and cost; } \\
\text { improve feasibility }\end{array}$ & $\begin{array}{l}\text { Able to collect complex information and } \\
\text { highly accurate data }\end{array}$ \\
\hline Limitations & Inherent bias related to self-report & $\begin{array}{l}\text { Inherent bias related to self-report; requires } \\
\text { participant training on how to use the } \\
\text { technology }\end{array}$ & $\begin{array}{l}\text { Measurement errors related to methodolo- } \\
\text { gy remain }\end{array}$ \\
\hline
\end{tabular}


In South Korea, the first FFQ was developed through modification of the FFQs used in Western countries to meet Korean diet characteristics [39]. After, some FFQs were developed following the opinion of experienced dietitians and epidemiologists based on the nutrient contents in Korean food and the results of previous studies [40-42]. Recent FFQs have been developed in a more sophisticated way using actual dietary data collected by the open-ended surveys. Among the various foods consumed by subjects, informative foods are selected according to the extent to which the foods contribute specific nutrients intakes or the extent that the foods explained between-persons variations [43-47]. Then the selected foods are grouped by their nutritional contents or cooking methods, and finally presented in a closed-ended format.

According to the interests of the researchers, FFQs may focus on the intake of specific nutrients $[48,49]$, dietary exposures related to a certain disease [43], or comprehensively assess various nutrients $[44,46,47]$. In prospective studies, comprehensive assessment is generally recommended because it enables us to assess any dietary components, which were not important at the beginning of a study but might emerge as an important factor later. Comprehensive assessment also enables us to estimate the intakes of various dietary components that might act as a confounder in relation to a key dietary factor and diseases, which allows for statistical adjustment.

According to the way which informative foods present in FFQs, food-based FFQs $[16,46,47]$ such as the Harvard FFQ [50,51] and dish-based FFQs $[43-45,52,53]$ have been developed. Korean and Asian food mainly contains many mixed dishes that are cooked with individual ingredient foods, seasonings, and cooking oils. Thus, food-based FFQs may raise subjects' burden and increase response error, when their subjects do not typically cook their food or are unaware of the ingredients. Moreover, the food-based FFQ [54] tends to underestimate dietary intake more than the dish-based FFQs do [44] because various seasonings (e.g., salt, soy sauce, red pepper paste, soybean paste, etc.) and cooking oils which are highly contributing to the nutrients (e.g., energy, fat, sodium, and $\beta$-carotene intake, etc.) intakes are not considered in dietary intake calculations $[55,56]$. Therefore, the dish-based approach has been recommended as a new strategy to improve dietary assessment in countries with an Asian diet [57-59].

Average consumption frequency can be assessed using openended questions [41], but most FFQs collect data across nine possible responses from never to three or more times per day. Various answer choices have been used to improve data quality and reduce the burden on the subjects [60]. For foods eaten seasonally, subjects are typically asked how frequently and over what duration they ate these seasonal foods $[42,44,47]$. For frequently consumed foods such as coffee, answers are collected directly as an open-ended question in some FFQs [44,61,62].

The utility of questions in FFQs about portion size has been controversial [4]: Some researchers reported that between-person variations in portion size were not important because that variation tends to be smaller than the variation in frequency of consumption [63]. In South Korea, however, data on the portion size of some foods seems to be important, such as cooked rice, because between-person variations might be highly explained by the portion size rather than the frequency [64]. Until now, semi-quantitative FFQs collecting data on the average portion sizes in a closed format have been more widely used in epidemiological studies [39,40,42-49,52,53,61,65-69] than has been the simple FFQs which solely asks about the frequency $[16,70]$ or quantitative FFQs which queries about the amount of food consumption using completely open-ended questions [41], respectively.

FFQs, which use a closed format, should be evaluated for their accuracy before being used as a dietary assessment tool in studies. A correlation coefficients ranging from 0.5 to 0.7 is considered moderate [4]; however, most FFQs from Asian countries including South Korea tend to have correlation coefficients ranging from 0.3 to 0.5 [40-43,61,66,67,71], which is lower than that from Western countries.

Some researchers questioned the value of using FFQs in epidemiological studies [11,12], and this topic continues to be highly debated [57,72-76]. In addition, concentrated efforts to assess usual dietary intakes accurately using FFQs as well as multiple 24HRs or DRs have been made. Newer techniques introduced FFQs that can be optically scanned, perform complex skip algorithms and probe multiple details, and range checks as well as allows for the presentation of pictures of foods for ease in reporting portion sizes. All of these efforts improve the quality of dietary data and enhance our capability to collect complex information.

\section{CONCLUSION}

Dietary intake is difficult to measure, and any single method cannot assess dietary exposure perfectly. Nutritional biomarkers are valid for objective estimates of dietary exposures in anthropometric and clinical assessment, while the 24HR, DR, dietary history, and FFQ are subjective estimates. Numerous efforts have made progress in the accuracy of dietary intake assessment methods, thus the feasibility of open-ended methods with various innovative technologies in epidemiological studies has been substantially enhanced. However, new methods needs higher costs than the FFQs, and intrinsic problems related to self-report remain unsolved. Notwithstanding the discussed limitations, FFQs are still widely used as the primary dietary 
assessment tool in epidemiological studies.

Recently, it has been suggested that a combination of methods, such as the FFQ with DRs (or 24HR) or the FFQ with biomarker levels, be used to obtain more accurate estimates of dietary intakes than that of individual methods. Considerable efforts to improve the accuracy and feasibility of large epidemiological studies are still ongoing.

In summary, dietary assessment methods should be selected with caution and while considering the research objective, hypothesis, design, and available resources.

\section{ACKNOWLEDGEMENTS}

This review was supported by a grant of the Korean Health Technology R\&D Project, Ministry of Health \& Welfare, Republic of Korea (HI13C0715).

\section{CONFLICT OF INTEREST}

The authors have no conflicts of interest to declare for this study.

\section{REFERENCES}

1. Doll R, Peto R. The causes of cancer: quantitative estimates of avoidable risks of cancer in the United States today. J Natl Cancer Inst 1981; 66:1191-1308.

2. Baik I, Cho NH, Kim SH, Shin C. Dietary information improves cardiovascular disease risk prediction models. Eur J Clin Nutr 2013;67: 25-30.

3. Streppel MT, Sluik D1, van Yperen JF1, Geelen A1, Hofman A, Franco $\mathrm{OH}$, et al. Nutrient-rich foods, cardiovascular diseases and all-cause mortality: the Rotterdam study. Eur J Clin Nutr 2014;68:741-747.

4. Nutrition epidemiology. New York: Oxford University Press; 1998.

5. Kim YJ, Kim OY, Cho Y, Chung JH, Jung YS, Hwang GS, et al. Plasma phospholipid fatty acid composition in ischemic stroke: importance of docosahexaenoic acid in the risk for intracranial atherosclerotic stenosis. Atherosclerosis 2012;225:418-424.

6. Kho M, Lee JE, Song YM, Lee K, Kim K, Yang S, et al. Genetic and environmental influences on sodium intake determined by using halfday urine samples: the Healthy Twin Study. Am J Clin Nutr 2013;98: 1410-1416.

7. Lim S, Shin H, Kim MJ, Ahn HY, Kang SM, Yoon JW, et al. Vitamin $\mathrm{D}$ inadequacy is associated with significant coronary artery stenosis in a community-based elderly cohort: the Korean Longitudinal Study on Health and Aging. J Clin Endocrinol Metab 2012;97:169-178.

8. Potischman N. Biologic and methodologic issues for nutritional biomarkers. J Nutr 2003;133 Suppl 3:875S-880S.

9. Kaaks R, Ferrari P, Ciampi A, Plummer M, Riboli E. Uses and limitations of statistical accounting for random error correlations, in the validation of dietary questionnaire assessments. Public Health Nutr 2002;5:969-976.
10. Wild CP, Andersson C, O’Brien NM, Wilson L, Woods JA. A critical evaluation of the application of biomarkers in epidemiological studies on diet and health. Br J Nutr 2001;86 Suppl 1:S37-S53.

11. Schatzkin A, Kipnis V, Carroll RJ, Midthune D, Subar AF, Bingham $\mathrm{S}$, et al. A comparison of a food frequency questionnaire with a 24hour recall for use in an epidemiological cohort study: results from the biomarker-based Observing Protein and Energy Nutrition (OPEN) study. Int J Epidemiol 2003;32:1054-1062.

12. Freedman LS, Potischman N, Kipnis V, Midthune D, Schatzkin A, Thompson FE, et al. A comparison of two dietary instruments for evaluating the fat-breast cancer relationship. Int J Epidemiol 2006; 35:1011-1021.

13. Fromme H, Gruber L, Schlummer M, Wolz G, Böhmer S, Angerer J, et al. Intake of phthalates and di(2-ethylhexyl)adipate: results of the Integrated Exposure Assessment Survey based on duplicate diet samples and biomonitoring data. Environ Int 2007;33:1012-1020.

14. Kim S, Moon S, Popkin BM. The nutrition transition in South Korea. Am J Clin Nutr 2000;71:44-53.

15. Margetts BM, Nelson M. Design concepts in nutritional epidemiology. New York: Oxford University Press; 1997.

16. Kweon S, Kim Y, Jang MJ, Kim Y, Kim K, Choi S, et al. Data resource profile: the Korea National Health and Nutrition Examination Survey (KNHANES). Int J Epidemiol 2014;43:69-77.

17. Dauchet L, Kesse-Guyot E, Czernichow S, Bertrais S, Estaquio C, Péneau S, et al. Dietary patterns and blood pressure change over 5-y follow-up in the SU.VI.MAX cohort. Am J Clin Nutr 2007;85:16501656.

18. Luke A, Bovet P, Forrester TE, Lambert EV, Plange-Rhule J, Schoeller DA, et al. Protocol for the modeling the epidemiologic transition study: a longitudinal observational study of energy balance and change in body weight, diabetes and cardiovascular disease risk. BMC Public Health 2011;11:927.

19. Illner AK, Freisling H, Boeing H, Huybrechts I, Crispim SP, Slimani $\mathrm{N}$. Review and evaluation of innovative technologies for measuring diet in nutritional epidemiology. Int J Epidemiol 2012;41:1187-1203.

20. Shriver BJ, Roman-Shriver CR, Long JD. Technology-based methods of dietary assessment: recent developments and considerations for clinical practice. Curr Opin Clin Nutr Metab Care 2010;13:548551.

21. Stumbo PJ. New technology in dietary assessment: a review of digital methods in improving food record accuracy. Proc Nutr Soc 2013; 72:70-76.

22. Moshfegh AJ, Rhodes DG, Baer DJ, Murayi T, Clemens JC, Rumpler WV, et al. The US Department of Agriculture Automated Multiple-Pass Method reduces bias in the collection of energy intakes. Am J Clin Nutr 2008;88:324-332.

23. Slimani N, Casagrande C, Nicolas G, Freisling H, Huybrechts I, Ocké $\mathrm{MC}$, et al. The standardized computerized 24-h dietary recall method EPIC-Soft adapted for pan-European dietary monitoring. Eur J Clin Nutr 2011;65 Suppl 1:S5-S15.

24. Schatzkin A, Subar AF, Moore S, Park Y, Potischman N, Thompson $\mathrm{FE}$, et al. Observational epidemiologic studies of nutrition and cancer: the next generation (with better observation). Cancer Epidemiol Biomarkers Prev 2009;18:1026-1032.

25. Jung HJ, Lee SE, Kim D, Noh H, Song S, Kang M, et al. Development and feasibility of a web-based program 'Diet Evaluation System (DES)' in urban and community nutrition survey in Korea. Korean J Health Promot 2013;13:107-115 (Korean).

26. Lieffers JR, Hanning RM. Dietary assessment and self-monitoring with nutrition applications for mobile devices. Can J Diet Pract Res 2012;73:e253-e260. 
27. Lee W, Chae YM, Kim S, Ho SH, Choi I. Evaluation of a mobile phone-based diet game for weight control. J Telemed Telecare 2010; $16: 270-275$.

28. Kikunaga S, Tin T, Ishibashi G, Wang DH, Kira S. The application of a handheld personal digital assistant with camera and mobile phone card (Wellnavi) to the general population in a dietary survey. J Nutr Sci Vitaminol (Tokyo) 2007;53:109-116.

29. Lacson R, Long W. Natural language processing of spoken diet records (SDRs). AMIA Annu Symp Proc 2006:454-458.

30. Rollo ME, Ash S, Lyons-Wall P, Russell A. Trial of a mobile phone method for recording dietary intake in adults with type 2 diabetes: evaluation and implications for future applications. J Telemed Telecare 2011;17:318-323.

31. Sun M, Fernstrom JD, Jia W, Hackworth SA, Yao N, Li Y, et al. A wearable electronic system for objective dietary assessment. J Am Diet Assoc 2010;110:45-47.

32. Long JD, Littlefield LA, Estep G, Martin H, Rogers TJ, Boswell C, et al. Evidence review of technology and dietary assessment. Worldviews Evid Based Nurs 2010;7:191-204.

33. Hercberg S. Web-based studies: The future in nutritional epidemiology (and overarching epidemiology) for the benefit of public health? Prev Med 2012;55:544-545.

34. Burke BS. The dietary history as a tool in research. J Am Diet Assoc 1947;23:1041-1046.

35. Bhupathiraju SN, Wedick NM, Pan A, Manson JE, Rexrode KM, Willett WC, et al. Quantity and variety in fruit and vegetable intake and risk of coronary heart disease. Am J Clin Nutr 2013;98:15141523.

36. Méjean C, Droomers M, van der Schouw YT, Sluijs I, Czernichow S, Grobbee DE, et al. The contribution of diet and lifestyle to socioeconomic inequalities in cardiovascular morbidity and mortality. Int $\mathrm{J}$ Cardiol 2013;168:5190-5195.

37. Nam CM, Oh KW, Lee KH, Jee SH, Cho SY, Shim WH, et al. Vitamin $\mathrm{C}$ intake and risk of ischemic heart disease in a population with a high prevalence of smoking. J Am Coll Nutr 2003;22:372-378.

38. Teufel NI. Development of culturally competent food-frequency questionnaires. Am J Clin Nutr 1997;65:1173S-1178S.

39. Kim MK, Choi BY, Shin YJ, Ahn YO, Lee SS, Cho YS. Semiquantitative food frequency method as an epidemiological tool in a rural community, Korea. Korean J Epidemiol 1994;16:54-65 (Korean).

40. Shim JS, Oh KW, Suh I, Kim MY, Sohn CY, Lee EJ, et al. A study on validity of a semi-quantitative food frequency questionnaire for Korean adults. Korean J Community Nutr 2002;7:484-494 (Korean).

41. Ji SK, Kim HS, Choi HM. A study on development and validation of food frequency questionnaire for estimating energy intake of women in child-bearing age. Korean J Community Nutr 2008;13:111-124 (Korean).

42. Hong S, Choi Y, Lee HJ, Kim SH, Oe Y, Lee SY, et al. Development and validation of a semi-quantitative food frequency questionnaire to assess diets of Korean type 2 diabetic patients. Korean Diabetes J 2010;34:32-39.

43. Park MK, Kim DW, Kim J, Park S, Joung H, Song WO, et al. Development of a dish-based, semi-quantitative FFQ for the Korean diet and cancer research using a database approach. Br J Nutr 2011;105: 1065-1072.

44. Yun SH, Shim JS, Kweon S, Oh K. Development of a food frequency questionnaire for the Korea National Health and Nutrition Examination Survey: data from the fourth Korea National Health and $\mathrm{Nu}-$ trition Examination Survey (KNHANES IV). Korean J Nutr 2013; 46:186-196 (Korean).

45. Kim YO, Kim MK, Lee SA, Yoon YM, Sasaki S. A study testing the usefulness of a dish-based food-frequency questionnaire developed for epidemiological studies in Korea. Br J Nutr 2009;101:1218-1227.

46. Kim J, Kim Y, Ahn YO, Paik HY, Ahn Y, Tokudome Y, et al. Development of a food frequency questionnaire in Koreans. Asia Pac J Clin Nutr 2003;12:243-250.

47. Ahn Y, Lee JE, Paik HY, Lee HK, Jo I, Kimm K. Development of a semi-quantitative food frequency questionnaire based on dietary data from the Korea National Health and Nutrition Examination Survey. Nutr Sci 2003;6:173-184.

48. Son SM, Huh GY, Lee HS. Development and evaluation of validity of dish frequency questionnaire (DFQ) and short DFQ using Na index for estimation of habitual sodium intake. Korean J Community Nutr 2005;10:677-692 (Korean).

49. Park YK, Kim Y, Park E, Kim JS, Kang MH. Estimated flavonoids intake in Korean adults using semiquantitative food-frequency questionnaire. Korean J Nutr 2002;35:1081-1088 (Korean).

50. Hu FB, Rimm E, Smith-Warner SA, Feskanich D, Stampfer MJ, Ascherio A, et al. Reproducibility and validity of dietary patterns assessed with a food-frequency questionnaire. Am J Clin Nutr 1999;69:243249.

51. Willett WC, Sampson L, Stampfer MJ, Rosner B, Bain C, Witschi J, et al. Reproducibility and validity of a semiquantitative food frequency questionnaire. Am J Epidemiol 1985;122:51-65.

52. Bae YJ, Choi HY, Sung MK, Kim MK, Choi MK. Validity and reproducibility of a food frequency questionnaire to assess dietary nutrients for prevention and management of metabolic syndrome in Korea. Nutr Res Pract 2010;4:121-127.

53. Na YJ, Lee SH. Development and validation of a quantitative food frequency questionnaire to assess nutritional status in Korean adults. Nutr Res Pract 2012;6:444-450.

54. Ahn Y, Lee JE, Cho NH, Shin C, Park C, Oh BS, et al. Validation and calibration of semi-quantitative food frequency questionnaire: with participants of the Korean Health and Genome Study. Korean J Community Nutr 2004;9:173-182 (Korean).

55. Shim JE, Ryu JY, Paik HY. Contribution of seasonings to nutrient intake assessed by food frequency questionnaire in adults in rural area of Korea. Korean J Nutr 1997;30:1211-1218 (Korean).

56. Yun SH, Choi BY, Kim MK. The effect of seasoning on the distribution of nutrient intakes by a food-frequency questionnaire in a rural area. Korean J Nutr 2009;42:246-255 (Korean).

57. Kristal AR, Peters U, Potter JD. Is it time to abandon the food frequency questionnaire? Cancer Epidemiol Biomarkers Prev 2005; 14 : 2826-2828.

58. Keshteli A, Esmaillzadeh A, Rajaie S, Askari G, Feinle-Bisset C, Adibi P. A Dish-based Semi-quantitative Food Frequency Questionnaire for Assessment of Dietary Intakes in Epidemiologic Studies in Iran: Design and Development. Int J Prev Med 2014;5:29-36.

59. Kobayashi T, Tanaka S, Toji C, Shinohara H, Kamimura M, Okamoto N, et al. Development of a food frequency questionnaire to estimate habitual dietary intake in Japanese children. Nutr J 2010;9:17.

60. Subar AF, Thompson FE, Smith AF, Jobe JB, Ziegler RG, Potischman $\mathrm{N}$, et al. Improving food frequency questionnaires: a qualitative approach using cognitive interviewing. J Am Diet Assoc 1995;95:781788.

61. Won HS, Kim WY. Development and validation of a semi-quantitative food frequency questionnaire to evaluate nutritional status of Korean elderly. Korean J Nutr 2000;33:314-323 (Korean).

62. Park MK, Noh HY, Song NY, Paik HY, Park S, Joung H, et al. Validity and reliability of a dish-based, semi-quantitative food frequency questionnaire for Korean diet and cancer research. Asian Pac J Cancer Prev 2012;13:545-552. 
63. Samet JM, Humble CG, Skipper BE. Alternatives in the collection and analysis of food frequency interview data. Am J Epidemiol 1984; 120:572-581.

64. Kim MK, Choi BY. The influence of portion size data on the agreement of classification of individuals according to nutrient estimates by food frequency questionnaire in a rural area of Korea. Nutr Res 2002;22:271-281.

65. Paik HY, Ryu JY, Choi JS, Ahn YJ, Moon HK, Park YS, et al. Development and validation of food frequency questionnaire for dietary assessment of Korean adults in rural area. Korean J Nutr 1995;28: 914-922 (Korean).

66. Kim MK, Lee SS, Ahn YO. Reproducibility and validity of a selfadministered food semiquantitative frequency questionnaire among middle-aged men in Seoul. Korean J Community Nutr 1996;1:376394 (Korean).

67. Kim WY, Yang EJ. A study on development and validation of food frequency questionnaire for Koreans. Korean J Nutr 1998;31:220230 (Korean).

68. Lim Y, Oh SY. Development of a semi-quantitative food frequency questionnaire for pre-school children in Korea. Korean J Community Nutr 2002;7:58-66 (Korean).

69. Lee HJ, Park SJ, Kim JH, Kim CI, Chang KJ, Yim KS, et al. Devel- opment and validation of a computerized semi-quantitative food frequency questionnaire program for evaluating the nutritional status of the Korean elderly. Korean J Community Nutr 2002;7:277-285 (Korean).

70. Kim J, Lee Y, Lee SY. Legumes and soy products consumption and functional disability in older women. Maturitas 2011;69:268-272.

71. Wakai K. A review of food frequency questionnaires developed and validated in Japan. J Epidemiol 2009;19:1-11.

72. Willett WC, Hu FB. The food frequency questionnaire. Cancer Epidemiol Biomarkers Prev 2007;16:182-183.

73. Willett WC, Hu FB. Not the time to abandon the food frequency questionnaire: point. Cancer Epidemiol Biomarkers Prev 2006;15:17571758.

74. Kelemen LE. Food frequency questionnaires: not irrelevant yet. Cancer Epidemiol Biomarkers Prev 2006;15:1054.

75. Kristal AR, Potter JD. Not the time to abandon the food frequency questionnaire: counterpoint. Cancer Epidemiol Biomarkers Prev 2006; 15:1759-1760.

76. Freedman LS, Schatzkin A, Thiebaut AC, Potischman N, Subar AF, Thompson FE, et al. Abandon neither the food frequency questionnaire nor the dietary fat-breast cancer hypothesis. Cancer Epidemiol Biomarkers Prev 2007;16:1321-1322. 